\title{
02 Mart 2017 Adıyaman-Samsat Depremi (M/=5.7) Artçı Şokları Kullanılarak Deprem İstatistiği Parametrelerinin Analizi ve Bölgesel Değişimleri
}

\author{
Nihan Hoşkan ${ }^{1, *}$ (i) \\ ${ }^{1}$ İstanbul Üniversitesi-Cerrahpaşa, Mühendislik Fakültesi, Jeofizik Mühendisliği Bölümü, 34320, İstanbul.
}

Özet

Bu çalışmada 02 Mart 2017 Adıyaman-Samsat Depremi $(M l=5.7)$ sonrasında meydana gelen artçı sarsintılar kullanılarak b-değeri ve artçı deprem azalım parametresi p-değerinin istatistiksel analizleri gerçekleştirilmiştir. Kandilli Rasathanesi ve Deprem Araştırma Enstitüsü (KOERI) ile Afet ve Acil Durum Yönetimi Başkanlı̆̆ (AFAD) kataloglarından derlenmiş 1345 artçı şok, yerel büyüklük Ml'ye göre derlenmiștir. Sonrasında, kayan pencereleme yöntemi ile tamlık magnitüdü Mc=1.6 elde edilmiş, en büyük olasılık yöntemi kullanılarak tüm bölge için ortalama b-değeri $0.768 \pm 0.03$ olarak hesaplanmıştır. Bu değer, tektonik depremlerde b için beklenen 1'e yakındır ve Gutenberg-Richter bağıntısı ile uyumludur. Geliștirilmiș Omori yasası ile tüm bölge için $p=0.91 \pm 0.05 c=0.041 \pm 0.030$ ve $K=25.6 \pm 3.21$ olarak hesaplanmıştır. Kabuk heterojenitesi, ısı akısı ve tektonik deformasyonla ilgili olabileceği düşünülen p-değerinin l'den küçük olması artçı şok azalım oranının nispeten yavaş olduğunu yansıtmaktadır. $b$-ve p-parametrelerinin bölgesel değissim haritaları $0.01^{\circ} \times 0.01^{\circ}$ grid aralığ ve her düğ̈̈̈m noktasına 450 deprem alınarak hazırlanmıstır. b-değeri 02 Mart 2017 (Ml=5.7) depreminin kuzeydoğu-güneybatı hattında yüksek ve bu depremin güney-güneydoğusunda düşük değer almıştır. Düşük b-değerinin yanında bölgede 24 Nisan 2018 (Ml=5.4) depreminin meydana gelmesi, bölgesel gerilmenin arttı̆̆ııın habercisi olabilir. p-değerinin bölgesel değişimi incelendiğinde, yüksek p-değeri Adıyaman-Samsat depreminin kuzey-kuzeydoğusundadır ve literatürde verilen InSAR haritasindaki deformasyon bölgesi ile hemen hemen uyumludur.

\section{Earthquake Statistical Parameters Analysis and Regional Variations of March 02, 2017 Adıyaman-Samsat Earthquake $(M /=5.7)$ by Using its Aftershocks}

\begin{abstract}
In this study, using the aftershocks that occurred after the March 02, 2017 Adlyaman-Samsat Earthquake (Ml = 5.7) statistical analyzes of b-value and aftershock decay parameter p-value were performed. 1345 aftershocks compiled from the catalogs of the Kandilli Observatory and Earthquake Research Institute (KOERI) and the Disaster \& Emergency Management Authority (AFAD) were homogenized according to the local magnitude Ml. Afterwards, the completeness magnitude Mc=1.6 was obtained with the moving time window approach and using maximum likelihood method, $b$-value was calculated as $0.768 \pm 0.03$ for the whole region. This value is close to the expected 1 for $b$ for tectonic earthquakes and is consistent with the Gutenberg-Richter relation. With modified Omori's Law $p=0.91 \pm 0.05, c=0.041 \pm 0.030$ and $K=25.6 \pm 3.21$ were calculated for the entire region. The $p$-value, which is thought to be related to crustal heterogeneity, heat flux and tectonic deformation, is less than 1, reflecting the relatively slow aftershock decay rate. Regional variation maps of $b$ - and p-parameters were prepared by taking 450 earthquakes at each node point with $0.01^{O} \times 0.01^{O}$ grid interval. The b-value was high in the northeast-southwest line of the March 02, $2017(\mathrm{Ml}=5.7)$ earthquake and low in the south-southeast of this earthquake. Besides the low b-value, the occurrence of the 24 April $2018(M l=5.4)$ earthquake in the region may foreshadow the increase in regional stress. Examining the regional variation of the p-value, the high p-value is in the north-northeast of the AdiyamanSamsat earthquake and is almost consistent with the deformation region on the InSAR map given in literature.
\end{abstract}

$\underline{\text { Keywords }}$

March 02, 2017 Adiyaman Samsat Earthquake, Spatial distribution of b-and p-values, Gutenberg-Richter Relation, Omori Law

\section{Giriş}

Büyük depremler sonrası kısa zamanda ve çok sayıda meydana gelen artçı şok dizisi, deprem bölgesinin tektonik yapısı, ana şokun kaynak özellikleri hakkında detaylı bilgi edinilmesi ve sismik tehlikenin anlaşılması açısından önemlidir (Wiemer ve Katsumata 1999; Öztürk ve Şahin 2019; Öztürk ve Ormeni 2021). 
Artçı şok dizisinin detaylı incelenmesi, büyük depremlerin karşılaştırılmasına imkan verir ve ana şokun meydana geldiği fay ya da bu fayla ilişkili ikincil fayların kırılma boyutlarının, konumunun, uzun zamandaki deprem etkinliğini kontrol eden mekanizmanın anlaşılmasını sağlar (Ogata 2001; Ogata vd. 2003; Öztürk ve Bayrak 2006; Utkucu vd. 2005). Artçı şoklar analiz edilerek deprem bölgesinin istatistiksel parametreleri pek çok araştırmacı tarafından incelenmiştir (Wiemer ve Wyss 2002; Enescu ve Ito 2002; Bayrak ve Öztürk 2004; Utkucu vd. 2005; Kutoğlu vd. 2008; Görgün vd. 2010; Öztürk 2011, Öztürk vd. 2008a; Öztürk vd. 2008b; Nemati 2014; Ávila-Barrientos vd. 2015; Raub vd. 2017; Meng vd. 2018; Öztürk ve Şahin 2019; Nanjo 2020).

Artçı sarsıntıların zamansal ve mekânsal dağılım modelleri ile ilgili en eski ve en önemli araştırmalardan biri Utsu (1969) tarafından yapılmıştır. Kisslinger (1993), arţ̧ı şok dağılımını kullanarak fay bölgelerinin fiziksel özelliklerini ve gerilme, sıcaklık, direnç gibi çevresel koşullarla olan ilişkisini incelemiştir. Aktif faylar boyunca uzaysal b-değer dağılımlarının haritalanması, gelecekteki bir depremde kırılma olasılığının yüksek olduğu varsayılan pürüzleri (düşük bdeğeri olan alanlar) belirlemek için kullanılmıştır (Wyss vd. 2000; Wyss 2001). Enescu ve Ito (2002), 2000 yılındaki Batı Tottori depremi sonrası meydana gelen artçı şok dizisini kullanarak yaptıkları çalışmada, düşük b değerine sahip alanların muhtemel yüksek gerilim altındaki bölgeler olduğunu; büyük p değerlerinin, ana şok sırasında büyük kayma yaşayan bölgelerle korelasyon gösterdiğini, küçük p değerlerinin ise genellikle önemli kırılma yaşanmayan bölgelerde elde edildiğini tespit etmişlerdir. Ayrıca, p-değerinin, kırılma sırasında üretilen sürtünme 1sısı ve/veya kabuktaki heterojenlik ile kontrol edilebileceğini de öne sürmüşlerdir. Schorlemmer vd. (2004), San Andreas Fayı Parkfield segmenti boyunca sismisiteyi incelemiş ve düşük ve yüksek değerli anomalilerin sırasıyla kilitli ve krip fay segmentleriyle ilişkilendirilebileceğini önermişlerdir. Öztürk ve Bayrak (2006), 31 Temmuz 2005 Ankara Bala Depremi artçı şok parametrelerinin bölgesel değişimleri ile ilgili yaptıkları çalışmada, düşük b ve p değerlerini alan bölgelerin, gelecekte olası deprem potansiyeline sahip bölgelere karşılık geldiği sonucuna varmışlardır. Öztürk ve Şahin (2019), artçı şok parametreleri, gerilme değişiklikleri ve sismik deformasyon arasında korelasyon olduğuna ve artçı şok dizisinin uzayzaman-büyüklük analizinin önemine vurgu yapmışlardır.

Adıyaman Samsat'ta 02 Mart 2017 tarihinde yerel saat ile 14:07.25'te Adiyaman Baraj1 yakınında Ml=5.7 büyüklüğünde deprem meydana gelmiştir. Depremde can kaybı olmamış, yapılarda hasar tespit edilmiştir (İmamoğlu vd. 2017; Özcan vd. 2017). Sismik olarak aktif olan bölgede meydana gelen depremlerin baraj kaynaklı tetikleme depremi olup olmadığı konusunda çalışmalar yapılmıştır. Eyidoğan vd. (2010) ve Eyidoğan ve Geçgel (2010) Atatürk Barajı rezervuarlarındaki su seviyesinindeki değişimleri incelemişler, 2007-2009 yılları arasında su seviyesindeki ani azalımların bölgedeki gerilimi değiştirdiğini ve bu azalım zamanlarında $\mathrm{M} l=3.8$ ve $\mathrm{M} l=5.1$ büyüklüğünde meydana gelen depremlerin tetikleme depremleri olduğunu, bölgede barajdaki su seviyesi değişiminden kaynaklanan depremlerin ileride de olabileceğini ileri sürmüşlerdir. Tatar vd. 2019, Yapay Açıklık Radar İnterferometrisi (InSAR) verileri ile bölgedeki yüzey deformasyonunu hesaplamışlar, Samsat beldesinin kuzeydoğusunda yoğunlaşan $2.78 \mathrm{~cm}$ 'lik faz değişimi tespit etmişlerdir. Bölgede meydana gelen 02 Mart 2017 Samsat (Ml=5.7) ve 24 Nisan 2018 (Ml=5.4) depremlerinin tetikleme depremi olmadıklarını, Samsat Fayının ürettiği depremler olduğunu ifade etmişlerdir.

Artçı şok dizileri kullanılarak yapılan sismik tehlike değerlendirmeleri, can ve mal kaybının yanı sıra, sosyal ve ekonomik olarak ortaya çıkacak sorunların asgari seviyeye indirgenebilmesi açısından önemlidir (Öztürk ve Şahin 2019; Öztürk ve Ormeni 2021). Artçı şok aktivitesi, depremlerin sayısı ile büyüklük dağılımı arasındaki ilişkiyi tanımlayan Gutenberg-Richter kanunu ve artçı şok aktivitesinin azalmasını tanımlayan geliştirilmiş Omori yasası olmak üzere iki temel ilişki ile incelenir. Bu çalışmada 02 Mart 2017 Adıyaman-Samsat depreminin $(\mathrm{M} l=5.7)$ artçı şoklarının istatistik özellikleri, Kandilli Rasathanesi ve Deprem Araştirma Enstitüsü (KOERI 2018) ve Afet ve Acil Durum Yönetimi Başkanlığı (AFAD 2018) deprem katalogları kullanılarak incelenmiştir. Artçı deprem dizilerinin istatistik özelliklerini incelemek için Gutenberg ve Richter (1954) yasasına göre b-değeri ve geliştirilmiş Omori yasasına göre p-değeri ZMAP paket programı (Wiemer 2001) kullanılarak hesaplanmıştır. b- ve p-değerlerinin bölgesel dağılımı haritalanarak artçı deprem etkinliği kullanılarak bölgenin sismik tehlikesi araştırılmıştır.

\section{Bölgenin Tektoniği}

02 Mart 2017 Adana-Samsat Depremi (Ml=5.7)'nin meydana geldiği Güneydoğu Anadolu Bölgesindeki en önemli tektonik yapı, Bitlis - Zagros Bindirme Zonu, bir diğer adıyla da Güneydoğu Anadolu Bindirme Kuşağıdır. Zon, Arap levhası ile Avrasya levhasının Orta Miyosen sonlarında başlayan çarpışma yeridir ve Adıyaman havzasının kuzey sınırını oluşturur. 1500 km uzunluğunda ve 60 km genişliğindeki bu kuşak, Kahramanmaraş ve Adıyaman çevresinden başlayıp, İran'da Zagros Kuşağı ile birleşir (Eyidoğan 1983) (Şekil 1). 


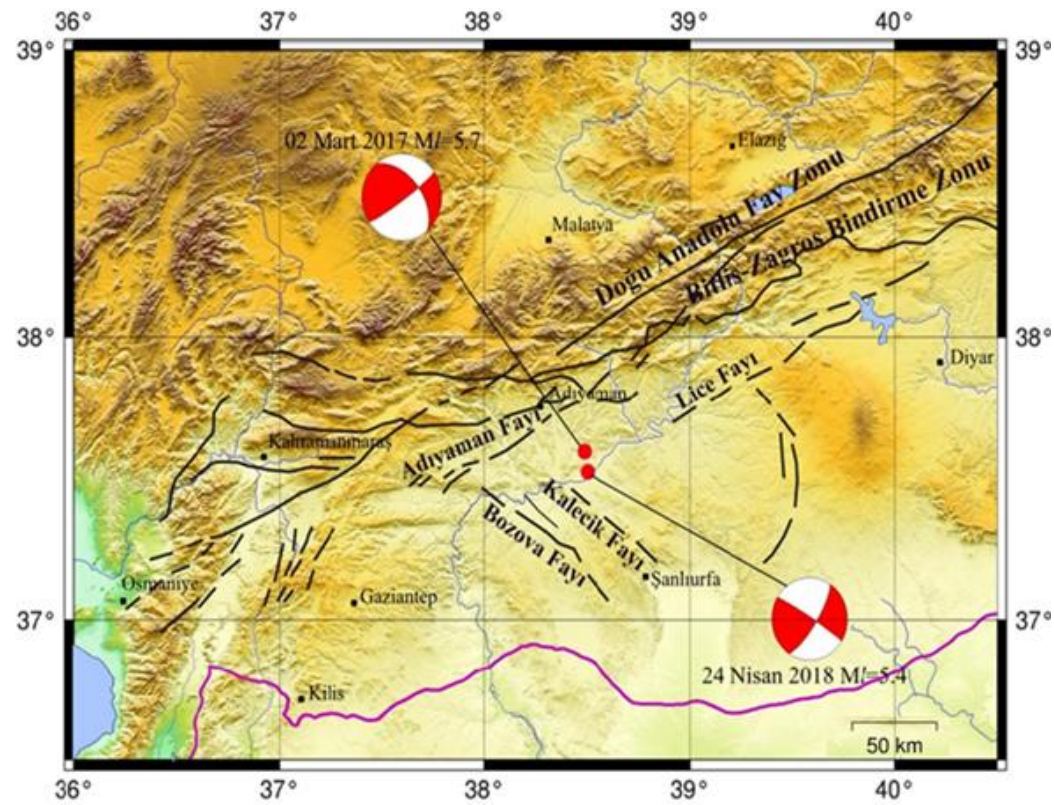

Şekil 1: Adıyaman ve çevresindeki önemli fay sistemleri ve 02 Mart 2017 Samsat (Ml=5.7) ve 24 Nisan 2018 (Ml=5.4) Samsat depremlerinin yeri ve odak mekanizma çözümleri (odak mekanizması çözümleri AFAD'dan alınmıştır) (İmamoğlu 2009'dan değiştirilmiştir)

Çalışma alanındaki diğer önemli faylar ise; 580 km uzunluğundaki Karlıova'dan Antakya’ya doğru yaklaşık KD-GB genel uzanımlı sol yanal doğrultu atımlı Doğu Anadolu Fay Zonu'dur (Şengör 1979; Şengör 1980). Adıyaman Fay Zonu, Doğu Anadolu Fay Zonunun R kırığı şeklinde görülen, ve bu zonun Palu ilçesi batısında ayrılıp güneybatıya dönerek Adıyaman'a devam eden Atatürk Barajı akısının hemen önünden ilerleyip Besni güneyinde çatallanıp kaybolan Miyosen yaşl1 $3 \mathrm{~km}$ genişliğinde, $210 \mathrm{~km}$ uzunluğundaki K60 D doğrultulu sol yanal atımlı bir fay zonudur (Sungurlu 1974; Perinçek vd. 1987, İnceöz vd. 2003; İnceöz ve Zengin 2014).

Lice Fay Zonu, Lice dolaylarından başlayıp Hani yakınlarında çatallanıp güney kolu Karacadağ bazaltlarına; kuzey kolu ise Dicle Nehri'nden güneybatıya devam eden Fırat Nehri'ne paralel uzanır ve sol yönlü atım yanı sıra düşey atım da bulunan fay zonudur (Eyidoğan 1983; Perinçek vd. 1987). Bu fay zonu üzerinde 1975 yılında Lice Depremi (Ms=6.6) meydana gelmiştir.

Bölgede gözlenen önemli ve aktif diğer bir fay, Doğu Anadolu Fay Zonunun X kırığı niteliğinde Adıyaman ili güneyinde belirginleşip Bozova'dan geçip Şanlıurfa merkez yakınlarında güneye dönen ve Akçakale grabeninin batı kenarını oluşturan KB-GD doğrultulu yaklaşık 50 km uzunluğunda yüksek açılı, sağ yönlü doğrultu atımlı Bozova fayıdır (Şengör vd. 1985; Şengör vd. 2008; Zengin 2005; Duman vd. 2012).

Kalecik Fayı, Bozova Fayının doğusunda, bu faya paralel olarak Lice Fay Zonu ile Doğu Anadolu Fay Zonunun bir X kırı̆̆ı niteliğinde gelişmiş, Bozova ile Hilvan arasında KB-GD yönlü uzanan sağ yanal doğrultu atımlı faydır (İmamoğlu 2009).

Bölgede, arazi gözlemleri ve 02 Mart $2017(M l=5.7)$ ile 24 Nisan $2018(M l=5.4)$ Adıyaman Samsat depremleri odak mekanizma çözümlerine dayanılarak, Yenilenmiş Türkiye Diri Fay haritasında bulunmayan, K40-50 ${ }^{\circ} \mathrm{B}$ gidişli sağ yanal doğrultu atımlı Bozova Fayına paralel Samsat Fayından bahsedilmektedir (Özcan vd. 2017; İmamoğlu vd. 2017; Tatar vd. 2019).

Tarihte, Pütürge segmentinde 1875'te M6.7 ve 1905'te M6.8, Erkenek segmentinde 1893 y1lında M7.2 büyüklüklerinde depremler meydana gelmiştir (Ambraseys 1988; Ambraseys ve Jackson 1998). AFAD deprem katalogundan yararlanılarak bölgede son yüzyılda 1964 Sincik-Adıyaman (Ms6.0), 1981 Gerger-Adıyaman (M5.0) ve 2010 Gerger-Adıyaman (M4.7) depremlerinin meydana geldiği tespit edilmiştir (AFAD 2018).

Özcan vd. 2017, 1980 sonrası meydana gelmiş $\mathrm{M} \geq 3.8$ olan büyük depremleri kullanarak oluşturdukları katalog yardımıyla bölgede yaklaşık 20 yılda bir M6.0, 65 yılda bir M6.5 ve 200 yılda bir de M7.0 büyüklüğünde deprem olabileceğini öne sürmüşlerdir.

\section{Materyal ve Yöntem}

02 Mart 2017 yılında yerel saatle 14:07.25'te meydana gelen depremin merkez üssü koordinatları AFAD tarafindan 37.5955(K), 38.4866(D) olarak verilmiştir (Şekil 2a, siyah yıldız). Depremin büyüklüğünü KOERI Ml=5.7, AFAD ve USGS Mw=5.6 olarak vermiştir. Odak derinliği 18 km (KOERI), 9.76 km (AFAD) ve 13.5 (USGS) olarak verilmiştir. Arazi gözlemleri sonucunda depremin, Samsat Fayı üzerinde oluştuğu ileri sürülmüştür (Özcan vd. 2017; İmamoğlu vd. 2017; Tatar vd. 2019). 
Bu çalışmada Samsat $\mathrm{Ml}=5.7$ depremini istatistiksel olarak incelemek ve bölgesel olarak analiz edebilmek için AFAD ve KOERI deprem kataloglarından derlenmiş artçı şok dizisi kullanılmıştır. Her iki deprem veri merkezi de 02 Mart 2017 Samsat depremi artçı şoklarının yerel büyüklüklerini hesaplamışlardır. Artçı şok dizisi için katalog oluşturulurken, veri merkezleri tarafından yerel büyüklükleri hesaplanmış olaylar derlenmiştir. AFAD ve KOERI'nin verdiği merkez üssü bilgisi kullanılmış (Şekil 2a), relokasyon yapılmamıştır. Çalışma için hazırlanan katalog, 02 Mart-01 Temmuz 2007 tarihleri arasındaki zaman diliminde $0.6 \leq \mathrm{M} l \leq 5.7$ büyüklükleri arasındaki 1345 artçı şoku içermektedir (Şekil 2b). Deprem sonrası meydana gelen en büyük artçı şok $\mathrm{M} l=4.6$ 'dır. Deprem sonrası ilk bir ay içinde $0.8 \leq \mathrm{M} l \leq 4.6$ aralığında 952 artçı şok oluşmuşken, haziran ayında $1.1 \leq \mathrm{M} l \leq 2.7$ aralığında 39 deprem meydana gelmiştir (Şekil $2 \mathrm{c}$ ). Bu nedenle, arţ̧ı şok kataloğu için seçilen zaman diliminin uygun olduğu düşünülmüştür.
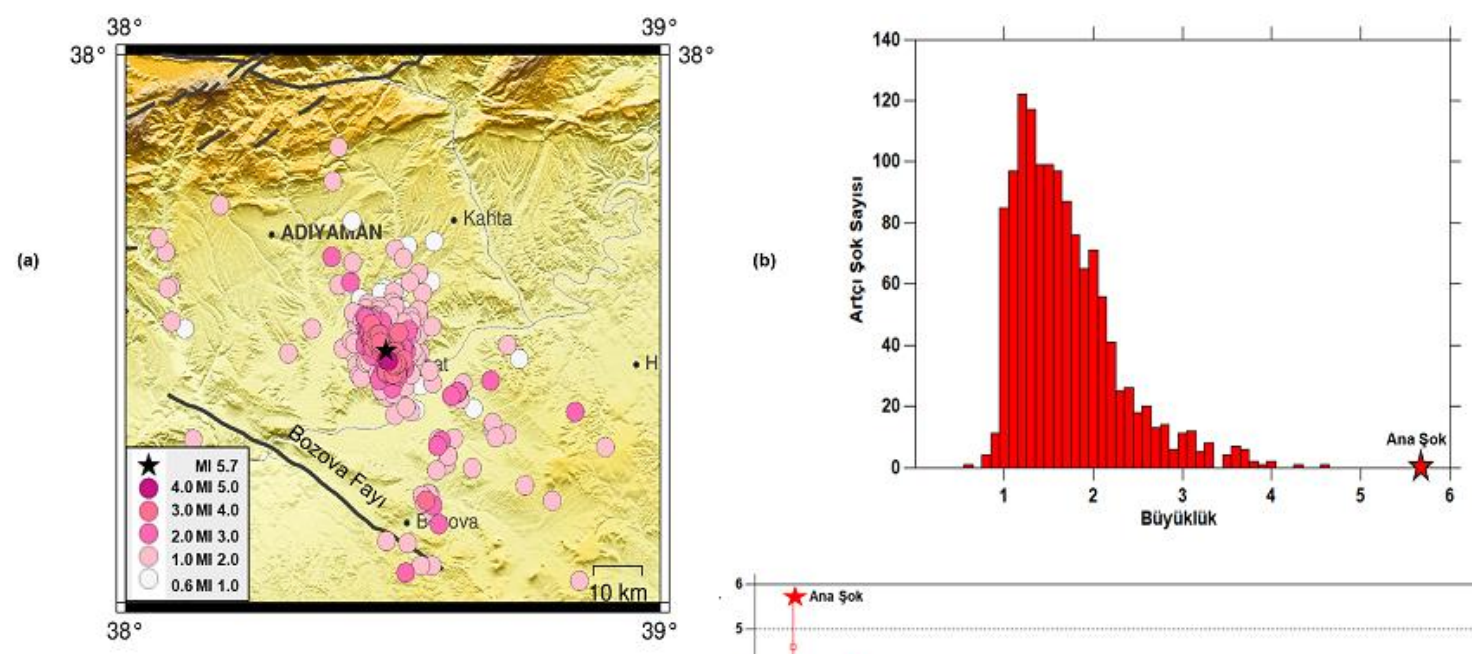

(c)

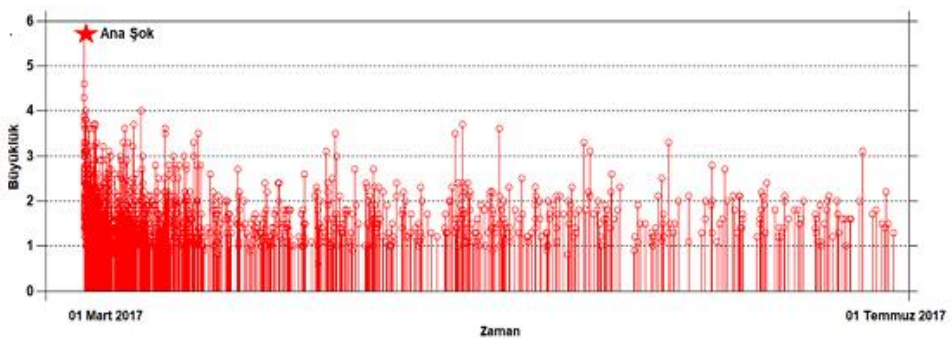

Şekil 2: 02 Mart 2017 Adıyaman-Samsat (MI=5.7) Depremi artçı sok dizisinin a) merkez üssü dağılımı (farklı büyüklükteki depremler farklı renklerle gösterilmiştir), b) büyüklük histogramı, c) Mart-Temmuz zaman dilimindeki büyüklük değişimleri

Deprem oluş sayısı-zaman grafiği Şekil 3'te verilmiştir. Bölgedeki artçı şoklar, deprem oluş zamanı ile Nisan ayı arasında hızlı bir artış göstermiş, nisan ayından temmuz ayına kadar doğrusal olarak artmaya devam etmiştir.

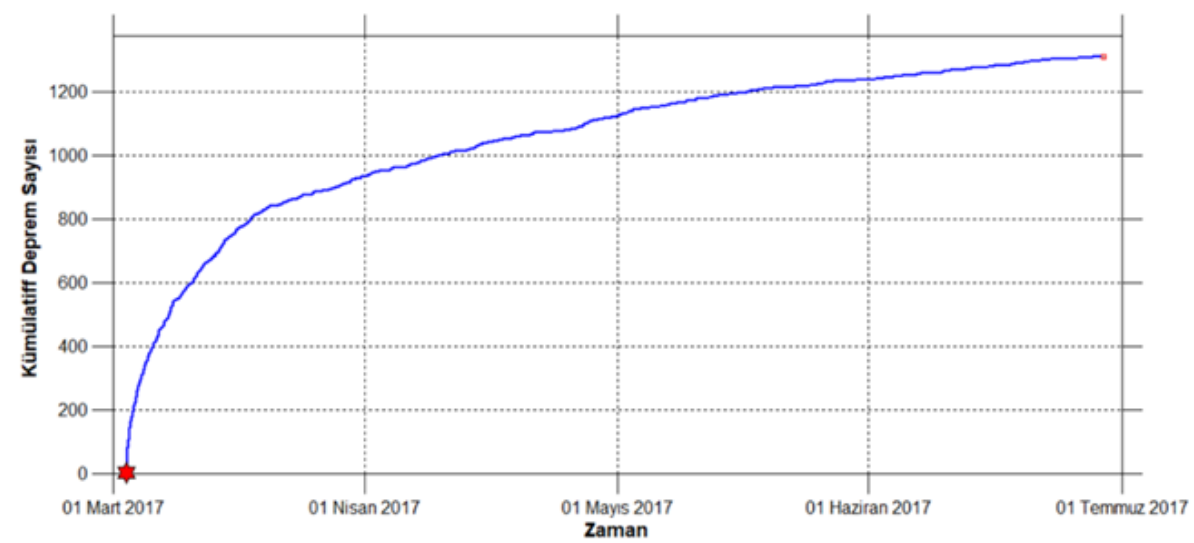

Şekil 3: 02 Mart 2007 Samsat (MI=5.7) Depremi kümülatif deprem sayısı- zaman dağılımı

Bu çalışmada, artçı şok etkinliğini tanımlayan iki temel ilişki kullanılmaktadır. Bunlardan ilki, deprem istatistiğinin temel bağıntısı olan ve depremlerin sayısı ile büyüklüğü arasındaki ilişkiyi tanımlayan Gutenberg-Richter (1954)

$\log N=a-b M$ 
bağıntısıdır. Burada, M; büyüklük, $\mathrm{N}$; büyüklüğü $\mathrm{M}$ veya daha büyük olan depremlerin belirli bir zaman aralığındaki sayısı, a; doğrunun $\log N$ eksenini kestiği nokta, b ise deprem oluş sayısı ile büyüklük dağılımının eğim miktarıdır. bdeğeri depremin meydana gelme fiziği ile ilgilidir (Mogi 1962; Scholz 1968). b değerlerindeki değişimler, sismotektonik bölgelendirme ve depremlerin önceden kestirilmesi çalışmalarında kullanılması açısından önemlidir. Büyük b-değeri zayıf bir gerilme azalımını, küçük b-değeri ise yüksek gerilme azalımını işaret eder (Lomnitz ve Singh 1976). a katsayısı, örneklenen zaman ve bölgedeki deprem sayısına bağlıdır ve büyük değerinin olması incelenen bölgedeki deprem aktivitesinin yüksek olduğunu gösterir.

Bu çalışmada b-değerinin belirlenmesi için, Türkiye ve çevresindeki depremlerin kümülatif frekanslarına en iyi uyan (Alptekin 1978) en büyük olasılık yöntemi (EBO) kullanılmıştır (Aki 1965; Shi ve Bolt 1982). Yöntemde,

$b=\frac{\log _{10} e}{\left(M_{\text {mean }}-M_{C}\right)}$

şeklindedir. Burada $M_{\text {mean }}$ ortalama büyüklük ve $M_{C}$ ise incelenen zaman aralığında deprem kataloğunun tamlık düzeyini gösteren tamlık veya kesme büyüklüğüdür.

Artçı şok etkinliğini tanımlayan ikinci temel ilişki ise, Omori Yasasıdır. Omori Yasası (1894), zamanın bir fonksiyonu olarak artçı şokların sayısının zamanla azaldığını gösterir (Utsu 1961). Dolayısı ile artçı şokların bölgesel dağılımları, ana şokun artçı şoklara neden olmasından kaynaklanan gerilme değişikliği ile ilişkilidir. Geliştirilmiş Omori yasası (Utsu 1961)

$n(t)=\frac{K}{(t+c)^{p}}$

şeklindedir. Burada, $t$ ana şoktan sonraki zaman, $n(t)$ ana şokun oluşumundan sonra $t$ birim zamana düşen artçı şokların oluşum sayısıdır. K, c, p ise zaman-deprem sayısı grafiğinden elde edilen sabitlerdir. K değeri depremlerin toplam sayısına bağlıdır. c değeri ise artçı şok dizisindeki en erken zaman aktivite oranı ile ilişkilidir ve 0.02 ile 0.5 değerleri arasında değişir (Hirata 1969, Öztürk ve Ormeni 2021). c-değeri genellikle ana şok kırılması sonu ile artçı şok azalma oranının başlangıcı arasındaki gecikme olarak kabul edilir (Narteau vd. 2009). Artçı şok dizisinin başlangıcındaki aktivite oranına bağlıdır (Öztürk ve Bayrak, 2006). Dizinin erken evresindeki küçük artçı şokların eksik tespiti ile güçlü bir şekilde etkilenir (Kisslinger ve Jones 1991). Bu parametreler içinde artçı şokların en önemli istatistiksel parametresi p-değeridir. $\mathrm{Bu}$ değer, artçı şokların üstel olarak azalma oranını belirler (Kisslinger 1996). Utsu vd. (1995), p-değerinin kabuksal heterojenite, gerilme şartları, 1sı akısı gibi tektonofiziksel koşullarla ilişkili olduğunu ve dolayısıyla, bölgeden bölgeye değişim göstereceğini belirtmişlerdir. p-değerinin büyük olması daha hızlı bir artçı şok azalım oranını yansıtırken, düşük p-değeri ise artçıların daha yavaş oranda azaldığını işaret etmektedir.

\section{Bulgular}

Bölgeye ait depremsellik katsayılarını ve bu parametrelerin bölgesel değişimini gözlemlemek amacıyla Wiemer (2001) tarafından geliştirilen ZMAP paket programı kullanılmıştır. Tamlık magnitüdü Mc'nin zaman içerisinde değişiminin incelenmesi için hareketli pencere tekniği kullanılmıştır. Pencere başına 10 deprem alınmıştır (Şekil 4). Ana şoktan sonraki ilk 10 saatte $\mathrm{Mc} \geq 3.1$ iken, ilk 20 günde $0.8 \leq \mathrm{Mc} \leq 2.6$ bandında değişim göstermiştir. Depremsellik çalışmalarında güvenilir sonuçlar, tüm büyüklük seviyelerinde eksiksiz veri setinin kullanılması ile mümkündür (Wiemer ve Wyss 2000). Maksimum olay sayısının kullanılması önerilmektedir (Öztürk ve Şahin 2019). Mc'nin doğru tahmini için veri setindeki olayların \%90’ını kapsaması gerekir (Wiemer ve Wyss 2000). Örnekleme aralığı, 20, 75 ve 150 deprem seçilerek hesaplanmış, sonuçların değişmediği görülmüştür. Deprem sayısı-büyüklük dağılımı için Mc=1.6 değeri alınmıştır.

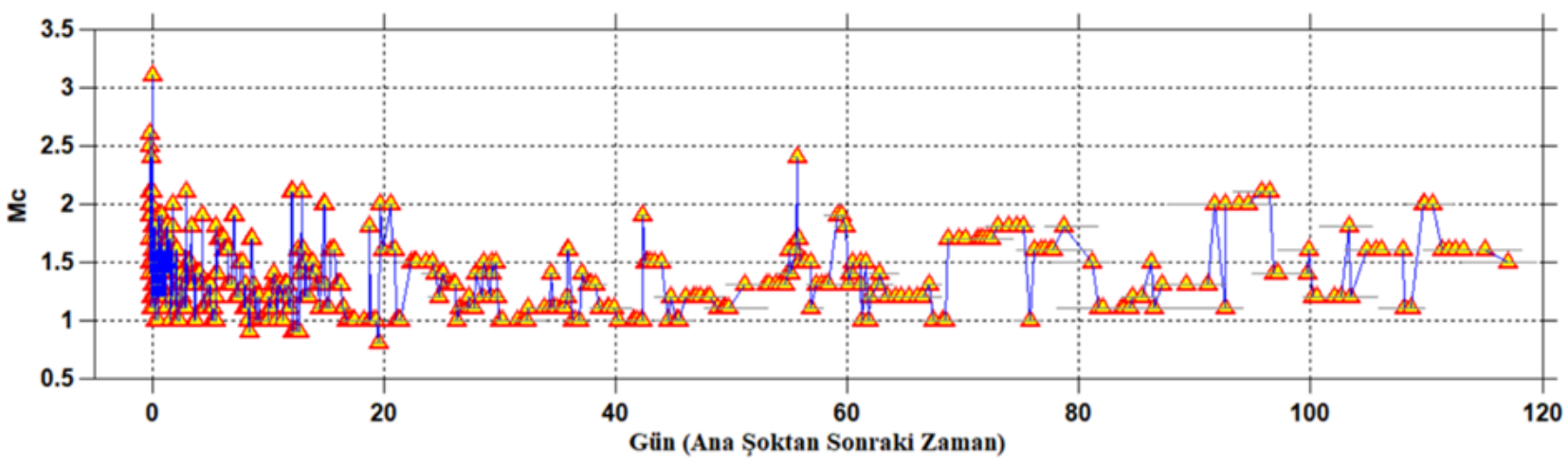

Şekil 4: Tamlık büyüklüğü Mc’nin zamansal değişimi (pencere başına 10 artçı şok alınmıştır) 
Çalışmada Gutenberg-Richter ilişkisindeki b-değeri EBO yöntemi kullanılarak hesaplanmıştır. Mc-değeri 1.6 olarak alınmış, \%95 güven aralığı içerisinde a-değeri 4.06 ve b-değeri $0.768 \pm 0.03$ olarak elde edilmiştir. Şekil 5, 02 Mart 2007 Samsat $(\mathrm{M} l=5.7)$ depremi ve artçı şokları için Gutenberg-Richter ilişkisini ve b-değerini göstermektedir. Elde edilen bdeğerinin Utsu (1971) ile Wiemer ve Katsumata (1999)'nın b için belirttikleri 0.3 ile 2.0 aralığı ile uyumlu olduğu görülmektedir.

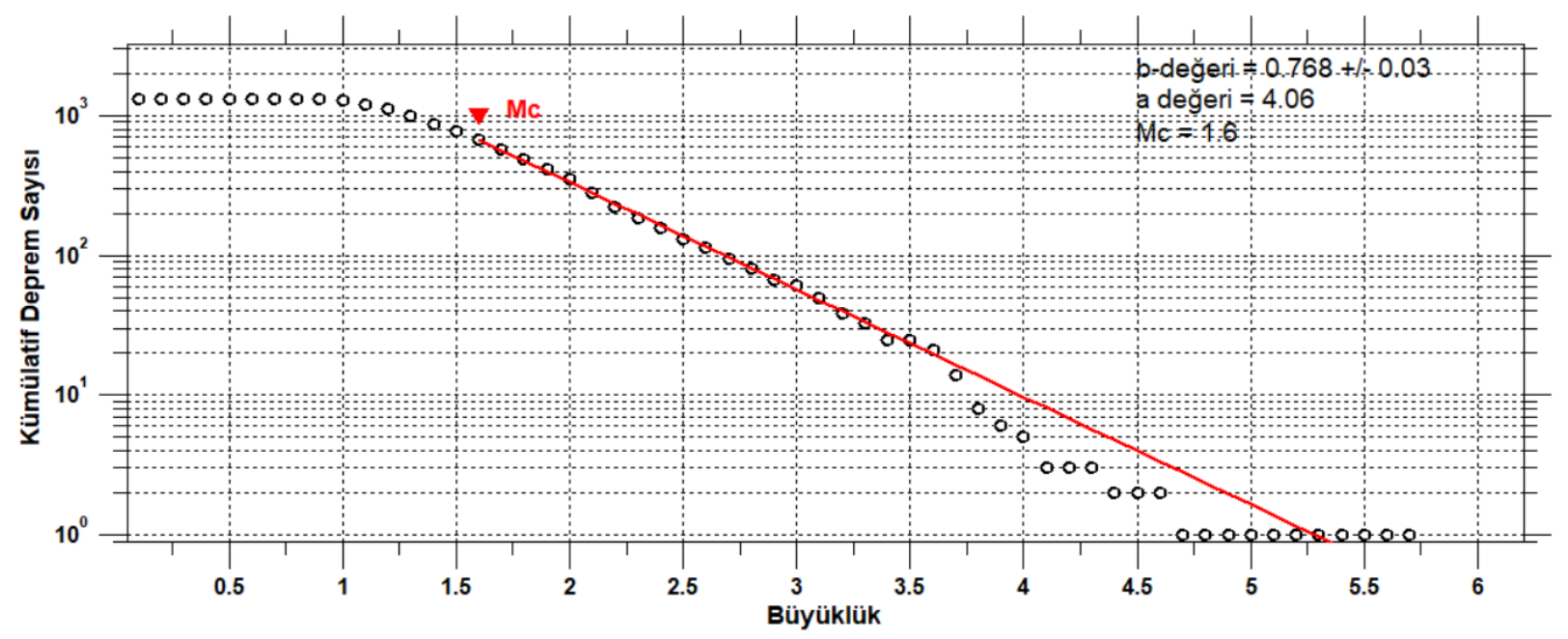

Şekil 5: 02 Mart 2007 Samsat (MI=5.7) Depremi ve artçı şoklar için frekans-büyüklük grafiği. Gutenberg-Richter ilişkisindeki a ve b-değerleri ile birlikte tamlık büyüklüğü şekil üzerinde verilmiştir

Tamlık analizi için minimum büyüklük başlangıcı $\left(\mathrm{M}_{\min }\right)$ ve minimum zaman başlangıcı $\left(\mathrm{T}_{\text {başlangıç})}\right.$ değerlerinin belirlenmesi gereklidir. p-değerinin hesabı için $\mathrm{Mc} \geq \mathrm{M}_{\min }$ olmak koşulu ile hesaplama yapılmalıdır (Öztürk ve Şahin 2019). Bu amaçla $\mathrm{T}_{\text {başlangıç }}$ için $0.1,0.05$ ve 0.01; $\mathrm{M}_{\min }$ için 1.6-2.5 arasındaki değerler hesaplanarak detaylı bir istatistik yapılmıştır (Tablo 1). Hesaplamalarda p-değerinin 0.83-1.1 arasında küçük değişimler gösterdiği tespit edilmiştir. cdeğerinin ise 0.214 ile 0.011 aralığında değiştiği gözlenmiştir. Çalışmada $\mathrm{T}_{\text {başlangıç }} 0.01 ; \mathrm{M}_{\min } 2.2$ alınarak, Mc değerinin zaman içindeki değişiminin neden olacağı hatalar engellenmeye çalışılmıştır. Geliştirilmiş Omori yasası kullanılarak elde edilen artçı şok dağılım eğrisi yardımıyla $\mathrm{p}=0.91 \pm 0.05 ; \mathrm{c}=0.041 \pm 0.030$ ve $\mathrm{K}=25.6 \pm 3.21$ olarak hesaplanmıştır (Tablo 1 ; 27. satır) (Şekil 6). p-değerinin genelikle 0.5-1.8 (Utsu vd. 1995; Wiemer ve Katsumata 1999); c-değerinin ise 0.02-0.5 (Utsu vd. 1995) değerleri arasında değiştiği bilinmektedir. Bu nedenle seçilen $\mathrm{M}_{\min }$ ve $\mathrm{T}_{\text {başlangıç değerlerinin uygun olduğu }}$ düşünülmüştür. Artçı şokların zamanla azalım oranı olan p-değeri, depremlerin fiziksel özellikleri ile ilişkilidir (Kisslinger 1996). Liu (1984) p-değerinin birden küçük olmasının bölgede yavaş deprem azalım oranını yansıttığını önermiştir. Buna göre bölgede nispeten daha yavaş bir arţ̧ı deprem etkinlik azalımı olduğu söylenebilir. 
Tablo 1: p-değeri hesabı için giriş verileri testi

\begin{tabular}{|c|c|c|c|c|c|c|c|}
\hline No & $M_{\min }$ & 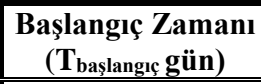 & $\begin{array}{c}\text { Zaman Aralı̆̆ı } \\
\text { (t gün) }\end{array}$ & p-değeri & c-değeri & K-değeri & $\begin{array}{c}\text { Kullanılan Artçı } \\
\text { Şok Sayısı } \\
\end{array}$ \\
\hline 1 & 1.6 & 0.1 & $0.10208 \leq \mathrm{t} \leq 118.6153$ & $0.87 \pm 0.04$ & $0.158 \pm 0.081$ & $80.26 \pm 8.99$ & 722 \\
\hline 2 & 1.7 & 0.1 & $0.10208 \leq \mathrm{t} \leq 118.6153$ & $0.86 \pm 0.04$ & $0.109 \pm 0.086$ & $65.52 \pm 8.12$ & 625 \\
\hline 3 & 1.8 & 0.1 & $0.10208 \leq \mathrm{t} \leq 118.6153$ & $0.86 \pm 0.04$ & $0.081 \pm 0.082$ & $53.88 \pm 6.96$ & 538 \\
\hline 4 & 1.9 & 0.1 & $0.10208 \leq \mathrm{t} \leq 118.6153$ & $0.86 \pm 0.04$ & $0.076 \pm 0.064$ & $43.89 \pm 5.58$ & 465 \\
\hline 5 & 2.0 & 0.1 & $0.10208 \leq \mathrm{t} \leq 118.6153$ & $0.84 \pm 0.04$ & $0.055 \pm 0.061$ & $35.12 \pm 4.70$ & 400 \\
\hline 6 & 2.1 & 0.1 & $0.10208 \leq \mathrm{t} \leq 118.6153$ & $0.95 \pm 0.07$ & $0.043 \pm 0.126$ & $28.86 \pm 5.76$ & 273 \\
\hline 7 & 2.2 & 0.1 & $0.10208 \leq \mathrm{t} \leq 118.6153$ & $0.95 \pm 0.07$ & $0.031 \pm 0.126$ & $28.87 \pm 5.76$ & 270 \\
\hline 8 & 2.3 & 0.1 & $0.10208 \leq \mathrm{t} \leq 118.6153$ & $0.95 \pm 0.07$ & $0.029 \pm 0.107$ & $22.40 \pm 4.57$ & 229 \\
\hline 9 & 2.4 & 0.1 & $0.10208 \leq \mathrm{t} \leq 118.6153$ & $0.98 \pm 0.08$ & $0.023 \pm 0.135$ & $20.42 \pm 4.79$ & 204 \\
\hline 10 & 2.5 & 0.1 & $0.10208 \leq \mathrm{t} \leq 118.6153$ & $1.1 \pm 0.12$ & $0.012 \pm 0.314$ & $18.05 \pm 8.52$ & 178 \\
\hline 11 & 1.6 & 0.05 & $0.050694 \leq \mathrm{t} \leq 118.6153$ & $0.87 \pm 0.03$ & $0.214 \pm 0.064$ & $78.52 \pm 8.30$ & 725 \\
\hline 12 & 1.7 & 0.05 & $0.050694 \leq \mathrm{t} \leq 118.6153$ & $0.86 \pm 0.04$ & $0.111 \pm 0.065$ & $64.49 \pm 7.35$ & 625 \\
\hline 13 & 1.8 & 0.05 & $0.050694 \leq \mathrm{t} \leq 118.6153$ & $0.86 \pm 0.04$ & $0.095 \pm 0.064$ & $54.54 \pm 6.47$ & 538 \\
\hline 14 & 1.9 & 0.05 & $0.050694 \leq \mathrm{t} \leq 118.6153$ & $0.87 \pm 0.04$ & $0.090 \pm 0.066$ & $46.70 \pm 5.95$ & 462 \\
\hline 15 & 2.0 & 0.05 & $0.050694 \leq \mathrm{t} \leq 118.6153$ & $0.86 \pm 0.04$ & $0.071 \pm 0.064$ & $37.55 \pm 5.05$ & 397 \\
\hline 16 & 2.1 & 0.05 & $0.050694 \leq \mathrm{t} \leq 118.6153$ & $0.89 \pm 0.05$ & $0.056 \pm 0.058$ & $31.59 \pm 4.467$ & 326 \\
\hline 17 & 2.2 & 0.05 & $0.050694 \leq \mathrm{t} \leq 118.6153$ & $0.95 \pm 0.06$ & $0.034 \pm 0.102$ & $29.17 \pm 5.38$ & 270 \\
\hline 18 & 2.3 & 0.05 & $0.050694 \leq \mathrm{t} \leq 118.6153$ & $0.95 \pm 0.07$ & $0.025 \pm 0.083$ & $22.75 \pm 4.22$ & 229 \\
\hline 19 & 2.4 & 0.05 & $0.050694 \leq \mathrm{t} \leq 118.6153$ & $0.97 \pm 0.07$ & $0.018 \pm 0.083$ & $19.55 \pm 3.85$ & 204 \\
\hline 20 & 2.5 & 0.05 & $0.050694 \leq \mathrm{t} \leq 118.6153$ & $1.01 \pm 0.09$ & $0.015 \pm 0.056$ & $18.21 \pm 4.46$ & 178 \\
\hline 21 & 1.6 & 0.01 & $0.010417 \leq \mathrm{t} \leq 118.6153$ & $0.84 \pm 0.03$ & $0.065 \pm 0.030$ & $72.12 \pm 6.05$ & 722 \\
\hline 22 & 1.7 & 0.01 & $0.010417 \leq \mathrm{t} \leq 118.6153$ & $0.83 \pm 0.03$ & $0.045 \pm 0.025$ & $59.69 \pm 5.06$ & 625 \\
\hline 23 & 1.8 & 0.01 & $0.010417 \leq \mathrm{t} \leq 118.6153$ & $0.83 \pm 0.03$ & $0.031 \pm 0.020$ & $49.28 \pm 4.26$ & 538 \\
\hline 24 & 1.9 & 0.01 & $0.010417 \leq \mathrm{t} \leq 118.6153$ & $0.84 \pm 0.03$ & $0.024 \pm 0.019$ & $41.79 \pm 3.76$ & 462 \\
\hline 25 & 2.0 & 0.01 & $0.010417 \leq \mathrm{t} \leq 118.6153$ & $0.83 \pm 0.03$ & $0.014 \pm 0.015$ & $33.92 \pm 3.14$ & 397 \\
\hline 26 & 2.1 & 0.01 & $0.010417 \leq \mathrm{t} \leq 118.6153$ & $0.86 \pm 0.04$ & $0.022 \pm 0.020$ & $28.85 \pm 3.07$ & 326 \\
\hline 27 & 2.2 & 0.01 & $0.010417 \leq \mathrm{t} \leq 118.6153$ & $0.91 \pm 0.05$ & $0.041 \pm 0.030$ & $25.60 \pm 3.21$ & 270 \\
\hline 28 & 2.3 & 0.01 & $0.010417 \leq \mathrm{t} \leq 118.6153$ & $0.92 \pm 0.05$ & $0.026 \pm 0.024$ & $20.30 \pm 2.63$ & 229 \\
\hline 29 & 2.4 & 0.01 & $0.010417 \leq \mathrm{t} \leq 118.6153$ & $0.93 \pm 0.05$ & $0.017 \pm 0.020$ & $17.19 \pm 2.26$ & 204 \\
\hline 30 & 2.5 & 0.01 & $0.010417 \leq \mathrm{t} \leq 118.6153$ & $0.92 \pm 0.05$ & $0.011 \pm 0.017$ & $13.90 \pm 1.91$ & 178 \\
\hline
\end{tabular}

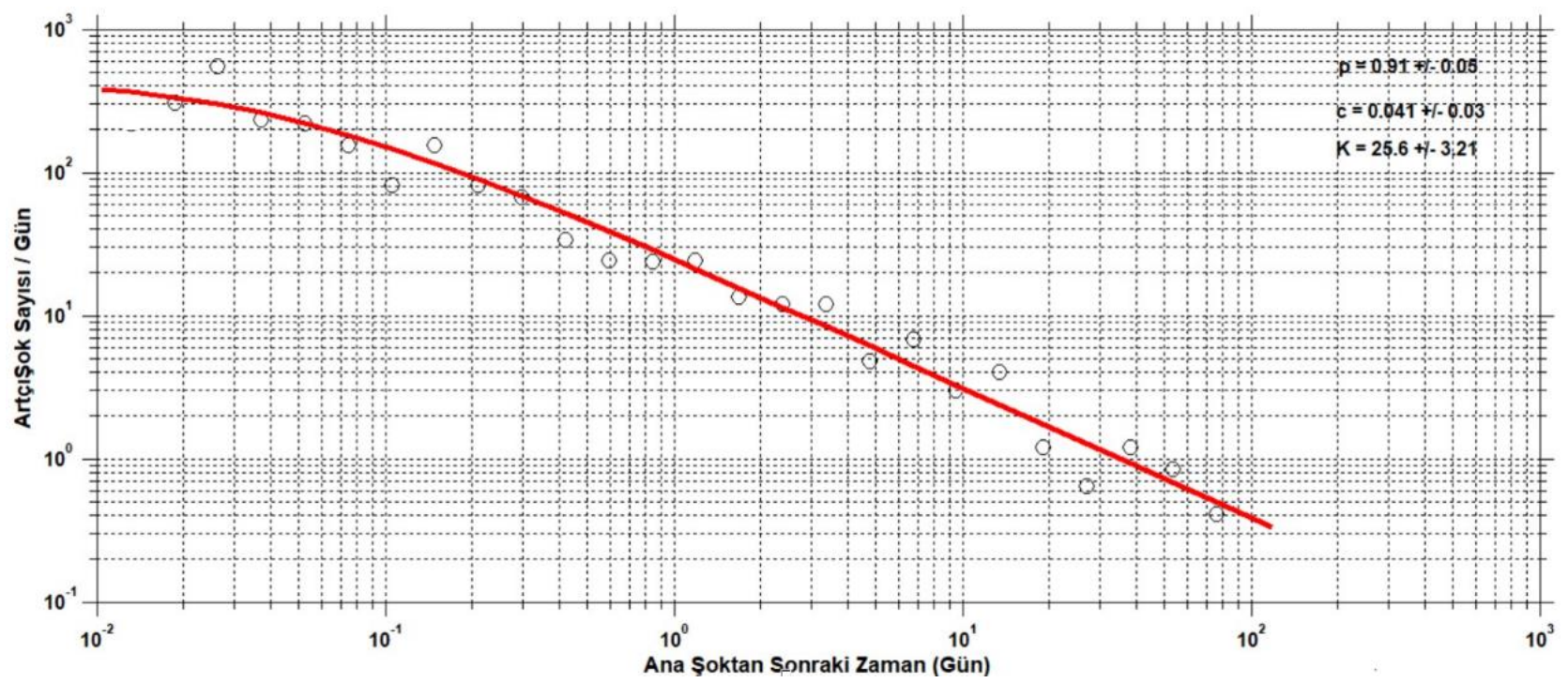

Şekil 6: 02 Mart 2007 Samsat Depremi (Ml=5.7) arţ̧ı şok azalım oranı. p, c ve K değerleri şekil üzerinde verilmiştir 
02 Mart 2007 Samsat (Ml=5.7) depremi ve artçı şokları için b- ve p-değerlerinin bölgesel değişimi, ZMAP programı kullanılarak, $0.01^{\circ} \times 0.01^{\circ}$ 'lik grid aralığı ile her bir düğüm noktasına en yakın 450 deprem atanarak EBO yöntemi ile hesaplanmıştır (Şekil 7). b-değeri bölgesel olarak 0.56 ile 0.83 arasına değişmektedir. Büyük b-değeri, 02 Mart 2017 $(\mathrm{M} l=5.7)$ Samsat depreminin kuzeydoğu-güneybatısında bir hat boyunca elde edilmiştir (Şekil 7a). b-değeri, deprem merkez üssünün kuzeydoğu-güneybatı hattında 0.75-0.83 arasında değişim gösterirken, merkez üssünün güneygüneydoğu kesiminde ise düşüktür. b-değerinin yerkabuğundaki gerilim ile ters orantılı olduğu bilinmektedir. Büyük bdeğeri bölgede düşük gerilmeye işaret ederken, tam tersi durum ise kabuktaki gerilmenin arttığını gösterir (Scholz 1968; Wiemer ve McNutt 1997; Urbancic vd. 1992, Wyss vd. 1997; Wiemer vd. 1998). 24 Nisan 2018 (Ml=5.4) Depremi (Şekil 1), 02 Mart 2017 (Ml=5.7) Samsat depremi merkez üssünün hemen güneydoğusunda, b-değerinin düşük olduğu bölgede meydana gelmiştir (Şekil7a, beyaz daire).

Bölgede p-değeri 0.9 ile 1.28 değer aralığında değişmekte, Samsat İlçesi kuzey-kuzeydoğusunda en yüksek değeri almaktadır (Şekil 7b). p-değeri değişimi üzerinde hangi parametrenin daha etkin olduğu tam olarak bilinemese de kabuktaki sıcaklık değişimi, heterojenite ve gerilimle ilişkilendirilebileceği önerilmiştir (Utsu vd. 1995; Mogi 1962; Kisslinger ve Jones 1991). Tatar vd. (2019), InSAR verileri yardımıyla bölgede özellikle Samsat İlçesi yakın kuzeydoğusunda deformasyonun yoğun olduğunu ifade etmişlerdir. Bu sonuç, Şekil 7b'de beyaz elips ile gösterilen pdeğerinin yüksek olduğu bölgeye hemen hemen denk düşmektedir.

(a)

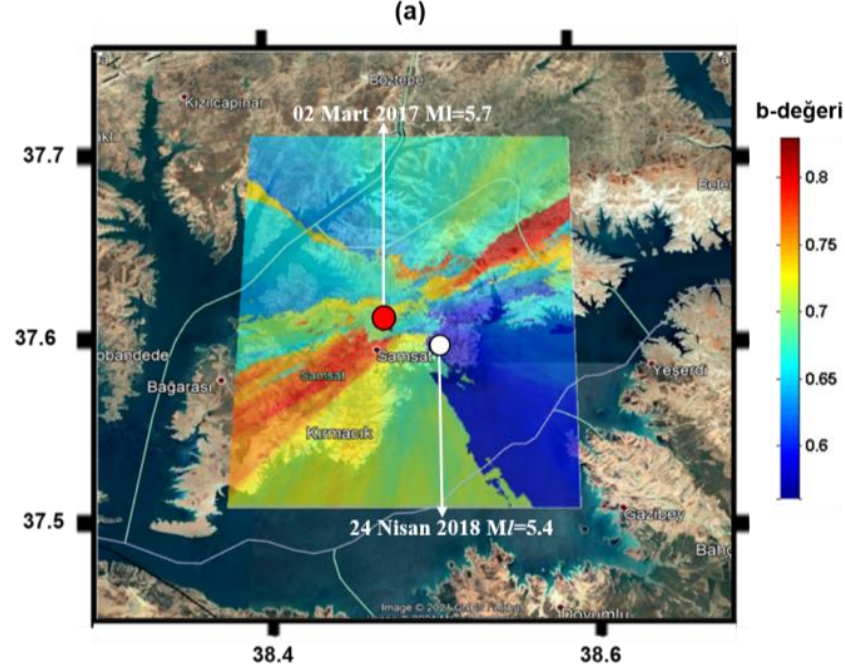

(b)

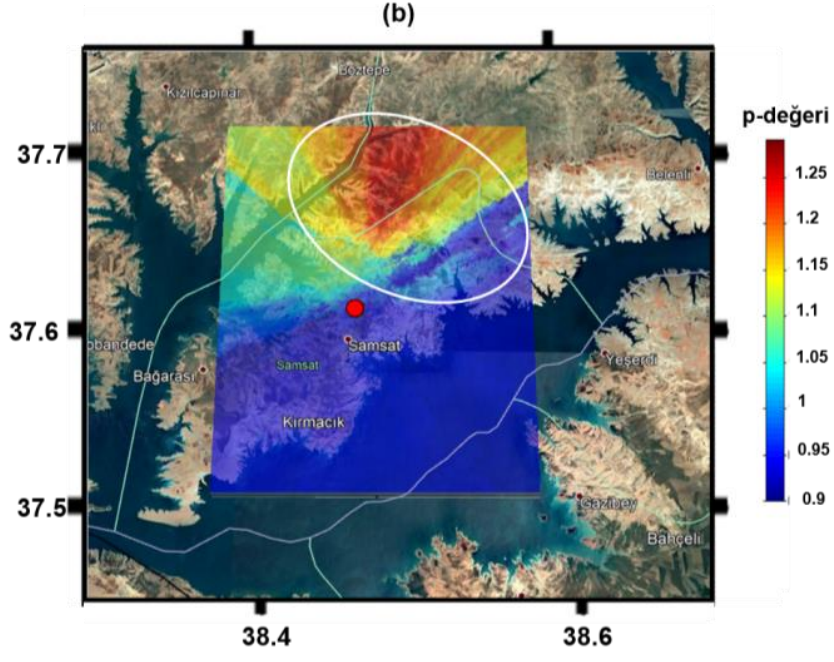

Şekil 7: 02 Mart 2007 Samsat (Ml=5.7) Depremi artçı şok dizisinden hesaplanan a) b-değerlerinin ve b) p-değerlerinin bölgesel değişim haritaları. Kırmızı yuvarlak 02 Mart 2017 (Ml=5.7), beyaz yuvarlak 24 Nisan 2018 (Ml=5.4) depreminin merkez üssünü; beyaz elips Tatar vd. (2019) tarafından InSAR verisi kullanılarak elde edilen yoğun deformasyon bölgesini göstermektedir

\section{Sonuçlar}

Bu çalışmada, 02 Mart 2017 Adıyaman-Samsat depremi (Ml=5.7) sonrası meydana gelen artçı şoklar kullanılarak bölgenin b- ve p- değerlerinin analizi yapılmıştır. Çalışmada kullanılan 1345 artçı şok KOERI ve AFAD kataloglarından yerel büyüklük $M l$ 'ye göre derlenmiştir. Tamlık büyüklüğü $\mathrm{M} c$, kayan pencereleme yöntemi ile 1.6 olarak bulunmuştur. Tüm bölge için b-değeri en büyük olasılık yöntemi ile $0.768 \pm 0.03$ olarak elde edilmiştir. Elde edilen b-değeri, tektonik depremlerde b-değerinin 1'e yakın bulunması beklendiğinden, Gutenberg-Richter bağıntısı ile uyumludur. Geliştirilmiş Omori yasası ile $\mathrm{M}_{\min } 2.2$, $\mathrm{T}_{\text {başlangıç }} 0.01$ alınarak $\mathrm{p}=0.91 \pm 0.05$; $\mathrm{c}=0.041 \pm 0.030$ ve $\mathrm{K}=25.6 \pm 3.21$ olarak hesaplanmıştır. Elde edilen p-değeri, bölgede yavaş deprem azalım oranının olduğunu gösterir. b-ve p-değeri bölgesel değişim haritaları, $0.01^{\mathrm{O}} \times 0.01^{\mathrm{O}}$ grid aralığı ve her düğüm noktasına 450 deprem alınarak hazırlanmıştır. b- değeri $02 \mathrm{Mart} 2017(\mathrm{M} l=5.7)$ depremi merkez üssünün kuzeydoğu-güneybatı yönündeki hat boyunca nispeten yüksek değer almıştır. 02 Mart 2017 $(\mathrm{M} l=5.7)$ depremi merkez üssünün güney-güneydoğusunda elde edilen düşük b-değeri, 24 Nisan 2018 (Ml=5.4) depreminin habercisi olabilir. Kabuk heterojenitesi, 1sı akıs1, tektonik deformasyonla ilgili olabilen p-değeri, Samsat İlçesi kuzeydoğusunda en büyük değeri almıştır ve bu sonuç bölgede Tatar vd. (2019) tarafından yapılmış InSAR verilerindeki deformasyon bölgesi ile hemen hemen uyumludur.

Sismik etkinlik bakımından aktif ve dünyanın üçüncü büyük barajı olan Atatürk Barajı'na yakın bir noktada meydana gelen 02 Mart $2017(\mathrm{Ml}=57)$ Samsat depreminin detaylı incelenmesi, bölgenin deprem riski ve deprem tehlikesinin aydınlatılması açısından oldukça önemlidir. Bu çalışmada elde edilmiş sonuçların bu bölge ve gelecekteki benzeri çalışmalar için önemli olduğu düşünülmektedir. 


\section{Teşekkürler}

Sayın Editöre ve önerileri ile çalışmanın gelişmesinde katkıda bulunan hakemlere teşekkür ederim. Çalışmadaki bazı şekiller için Wessel ve Smith (1998) tarafından geliştirilmiş Generic Mapping Tools (GMT) kullanılmıştır.

\section{Kaynaklar}

AFAD, (2018), T.C. İçişleri Bakanlı̆̆ı, Afet ve Acil Durum Yönetimi Başkanlığı, Deprem Dairesi Başkanlığ1, 1900 - 20xx Deprem Kataloğu(M > = 4.0), https://deprem.afad.gov.tr/depremkatalogu, [Erişim 10 Ocak 2018].

Aki K., (1965), Maximum likelihood estimate of $b$ in the formula $\log N=a-b M$ and its confidence limits, Bulletin of the Earthquake Research Institute, University of Tokyo, 43(2), 237-239.

Alptekin Ö., (1978), Magnitude-frequency relationships and deformation release for the earthquakes in and around Turkey, Thesis for Promoting to Associate Professor Level, Karadeniz Technical University, 107ss.

Ambraseys N.N., (1988), Engineering seismology, Earthquake Engineering and Structural Dynamics, 17, 1-105.

Ambraseys N.N., Jackson J.A., (1998), Faulting associated with historical and recent earthquakes in the Eastern Mediterranean Region, Geophysical Journal International, 133(2), 390-406.

Ávila-Barrientos L., Zúñiga F.R., Rodríguez-Perez Q., Guzmán-Speziale M., (2015), Variation of $b$ and $p$ values from aftershocks sequences along the Mexican subduction zone and their relation to plate characteristics, Journal of South American Earth Sciences 63, 162-171.

Bayrak Y., Öztürk S., (2004), Spatial and temporal variations of the aftershock sequences of the 1999 İzmit and Düzce earthquakes, Earth Planets Space, 56(10), 933-944.

Duman T.Y., Emre Ö., Özalp S., Olgun Ş., Elmacı H., (2012), 1:250.000 ölçekli Türkiye diri fay haritası serisi, Şanlıurfa (NJ 37-10) ve Suruç (NJ37-14) paftalarl, Seri No 43, Maden Tetkik ve Arama Genel Müdürlügü, Ankara.

Enescu B., Ito K., (2002), Spatial analysis of the frequency-magnitude distribution and decay rate of aftershock activity of the 2000 Western Tottori earthquake, Earth Planets Space, 54(8), 847-859.

Eyidoğan H., (1983), Bitlis-Zagros kıtasal çarpışma kuşağ boyunca etkin sı̆̆ deformasyonlar ve depremler arasındaki ilişkiler, Deprem Araştırma Bülteni, 43(1983), 63-99.

Eyidoğan H., Geçgel V., (2010), Atatürk Barajı su düzeyi ve tetiklenmiş depremsellik ilişkileri, 1992-2009, Aktif Tektonik Araştırma Grubu 14. Çalıştayı, 03-06 Kasım, Adıyaman Üniversitesi, Bildiri Özleri Kitapçı̆̆ı, s.31.

Eyidoğan H., Geçgel V., Pabuçcu Z., (2010), 3 Eylül 2008 Atatürk Barajı depremi: Tetiklenmiş depremsellik ve Bozova fayl, 63.Türkiye Jeoloji Kurultayı, Bildiri Özleri Kitapçığı.

Görgün E., Bohnhoff M., Bulut F., Dresen G., (2010), Seismotectonic setting of the Karadere-Duzce Branch of the North Anatolian Fault Zone between the 1999 Izmit and Düzce Ruptures from Analysis of Izmit after- shock focal mechanisms, Tectonophysics, 482(1-4), 170-181.

Gutenberg R., Richter C.F., (1954), Seismicity of the Earth and associated phenomenon, 2nd ed., Princeton Univ. Press, Princeton, N.J., 310ss.

Hirata T., (1969), Aftershock sequence of the earthquake off Shikotan Island on January 29, 1968, Geophysical Bulletin of Hokkaido University, 21, 33-43.

İmamoğlu M.Ș., Öncü M.E., Bedirhanoğlu İ., Şimşek Z., (2017), 02 Mart 2017 Adlyaman Samsat depremi ön değerlendirme raporu, Dicle Üniversitesi Mühendislik Fakültesi ve TMMOB İnşaat Mühendisleri Odası Diyarbakır Şubesi, 04 Mart 2017, ss.1-20.

İmamoğlu Ş.M., (2009), Tektonik Yapısı ve Stratigrafisi Işı̆̆ııda Güneydoğu Anadolu Bölgesinin Jeotermal Enerji Potansiyelinin Değerlendirilmesi, V. Yenilenebilir Enerji Kaynakları Sempozyumu, 19-21 Haziran, Diyarbakır, ss.161-166.

İnceöz M., Zengin E., (2014), Adlyaman fay zonunun morfotektonik ve yapısal özellikleri, Firat Üniversitesi Mühendislik Bilimleri Dergisi, 26(2), 131-148.

İnceöz M., Aksoy E., Zengin E., (2003), Adıyaman fay zonunun Palu-Fırat Nehri arasındaki bölümünün morfotektonik özellikleri, TAG-7 Aktif Tektonik Araştırma Grubu 7. Toplantısı, Yüzüncüyıl Üniversitesi Jeoloji Mühendisliği Bölümü, 01-03 Ekim, Van.

Kisslinger C., Jones L.M., (1991), Properties of aftershock sequences in Southern California, Journal of Geological Research, 96(B7), 11947-11958.

Kisslinger, C., (1993), The stretched exponential function as an alternative model for aftershock decay rate, Journal of Geological Research, 98, 1913-1921.

Kisslinger C., (1996), Aftershocks and Fault-Zone properties, Advances in Geophysics, 38, 1-36.

KOERI, (2018), Boğaziçi Üniversitesi Kandilli Rasathanesi ve Deprem Araştırma Enstitüsü (KOERI) Bölgesel Deprem-Tsunami İzleme ve Değerlendirme Merkezi (BDTIM) Deprem Sorgulama Sistemi, http://www.koeri.boun.edu.tr/sismo/zeqdb/, [Erişim 10 Ocak 2018].

Kutoğlu Ş.H., Akçın H., Kemaldere H., Görmüş K.S., (2008), Triggered Creep Rate on the Ismetpasa Segment of the North Anatolian Fault, Natural Hazards and Earth System Sciences, 8(6), 1369-1373.

Liu Z.R., (1984), Earthquake frequency and prediction, Bulletin of the Seismological Society of America, 74(1), 255-265.

Lomnitz C., Singh S.K., (1976), Earthquakes and earthquake prediction, Seismic Risk and Engineering Decisions'ın İçinde, (Lomnitz C. and Rosenblueth E., Ed.), Elsevier Scientific Publishing Company, ss.3-30.

Meng L., Bao H., Huang H., Zhang A., Bloore A., Liu Z., (2018), Double pincer movement: Encircling rupture splitting during the 2015 Mw 8.3 Illapel earthquake, Earth and Planetary Science Letters, 495(2018), 164-173.

Mogi K., (1962), On the time distribution aftershocks accompanying the recent major earthquakes in and near Japan, Bulletin of the Earthquake Research Institute, University of Tokyo, 40(1), 107-124.

Nanjo K.Z., (2020), Were changes in stress state responsible for the 2019 Ridgecrest, California, earthquakes? Nature Communications, 11(1), 1-10. 
Narteau C., Byrdina S., Shebalin P., Schorlemmer D., (2009), Common dependence on stress for the two fundamental laws of statistical seismology, Nature 462(7273), 642-645.

Nemati M., (2014), An appraisal of aftershocks behavior for large earthquakes in Persia, Journal of Asian Earth Sciences, 79(2014), 432-440.

Ogata Y., (2001), Increased probability of large earthquakes near aftershock regions with relative quiescence, Journal of Geophysical Research: Solid Earth, 106(B5), 8729-8744.

Ogata Y., Jones L.M., Toda S., (2003), When and where the aftershock activity was depressed: Contrasting decay patterns of the proximate large earthquakes in southern California, Journal of Geophysical Research: Solid Earth, 108(B6), 2318.

Omori F., (1894), On aftershocks of earthquakes, J. Coll. Sci. Imp., University of Tokyo, 7, 111-200.

Özcan Z., Özocak A., Utkucu M., Doğan E., (2017), Preliminary report on the March 2, 2017 Samsat (Adiyaman) earthquake, Rapor No:2017-2, Sakarya Üniversitesi, Afet Yönetim Uygulama ve Araştırma Merkezi.

Öztürk S., Bayrak Y., (2006), 31 Temmuz 2005 Bala (Ankara) Depremi, MD=4.9, Artçı Şok Dizisinin İstatistiksel Olarak Değerlendirilmesi ve Artçı Şok Parametrelerinin Bölgesel Değişimleri, Journal of İstanbul Kültür University, 4(2), 145-155.

Öztürk S., Bayrak Y., Çınar H., Koravos G.Ch., Tsapanos T.M., (2008a), A quantitative appraisal of earthquake hazard parameters computed from gumbel $\mathrm{l}$ method for different regions in and around Turkey, Natural Hazards, 47(3), 471-495.

Öztürk S., Çınar H., Bayrak Y., Karslı H., Daniel G., (2008b), Properties of the aftershock sequences of the 2003 Bingöl, MD=6.4, (Turkey) earthquake, Pure and Applied Geophysics, 165(2), 349-371.

Öztürk S., (2011), Characteristics of Seismic Activity in the Western, Central and Eastern Parts of the North Anatolian Fault Zone, Turkey: Temporal And Spatial Analysis, Acta Geophysica, 59(2), 209-238s.

Öztürk S., Şahin S., (2019), A statistical space-time-magnitude analysis on the aftershocks occurrence of the July 21 th, 2017 MW=6.5 Bodrum-Kos, Turkey, earthquake, Journal of Asian Earth Sciences, 172, 443-457.

Öztürk S., Ormeni R., (2021), An evaluation on the behaviors of aftershock sequence of November 26th, 2019 Earthquake, ML=6.3, North of Durrës, Albania, MSU J. of Sci., 9(1), 817-826.

Perinçek D., Günay Y., Kozlu H., (1987), Doğu ve Güneydoğu Anadolu bölgesindeki yanal atımlı faylar ile ilgili yeni gözlemler, TMMOB Petrol Mühendisleri Odas1 Türkiye 7. Petrol Kongresi, 6-10 Nisan, Ankara, ss.89-103.

Raub C., Martinez-Garzon P., Kwiatek G., Bohnhoff M., Dresen G., (2017), Variations of seismic b-value at different stages of the seismic cycle along the North Anatolian Fault Zone in Northwestern Turkey, Tectonophysics, 712(2017), 232-248.

Scholz C.H., (1968), The frequency-magnitude relation of microfracturing in rock and its relation to earthquakes, Bulletin of the seismological society of America, 58(1), 399-415.

Shi Y., Bolt B.A., (1982), The standard error of the magnitude-frequency b value, Bulletin of the Seismological Society of America 72(5), 1677-1687.

Schorlemmer D., Wiemer S., Wyss M., (2004), Earthquake statistics at Parkfield: 1.Stationarity of b values, Journal of Geophysical Research: Solid Earth, 109(B12), doi:10.1029/2004JB003234.

Sungurlu O., (1974), VI. Bölge kuzey sahalarının jeolojisi, TPAO Arama Grubu, Rapor No: 871, Ankara, 32ss.

Şengör A.M.C., (1980), Türkiye'nin neotektoniğinin esasları, Türkiye Jeoloji Konferanslar Serisi Yayınları No: 2, Ankara, 40ss.

Şengör A.M.C., (1979), The North Anatolian transform fault: Its age, ofset and tectonic significance, Journal of the Geological Society, 136(3), 269-282.

Şengör A.M.C., Görür N., Şaroğlu F., (1985), Strike-Slip deformation basin formation and sedimentation: Strike-Slip faulting and related basin formation in zones of tectonic escape: Turkey as a case study, In: Biddle KT, Christie-Blick N, editors. Strikeslip faulting and basin formation. Soc Econ Paleontol Min Spec Publ 37, 227-264.

Şengör A.M.C., Özeren M.S., Keskin M., Sakınç M., Özbakır A.D., Kayan İ., (2008), Eastern Turkish High Plateau as a small TurkicType Orogen: Implications for post-collisional crust-forming processes in Turkic-Type Orogens, Earth-Science Reviews, 90(1), 148.

Tatar O., Koçbulut F., Polat A., Demirel M., (2019), 02.03.2017 and 24.04.2018 Samsat (Adiyaman) Earthquakes and Their Importance in Regional Seismotectonics, Geological Bulletin of Turkey, 62(2), 167-180.

Urbancic T.I., Trifu C.I., Long J.M., Toung R.P., (1992), Space-Time correlations of b value with stress release, Pure and Applied Geophysics, 139(3), 449-462.

Utkucu M., Çetin C., Alptekin Ö., (2005), 12 Kasım 1999 Düzce depremi artçı depremlerinden hesaplanan b ve p değerlerinin uzay ve zaman dă̆llımı ve gelecekteki sismik tehlike hakkında değerlendirmeler, Yerbilimleri (Earth Sciences), 26(1), 75-91.

Utsu T., (1961), A statistical study on the occurrence of aftershocks, Geophys. Mag., Tokyo, Japan, 30, 521-603.

Utsu T., (1969), Aftershocks and earthquake statistics (I)-Some parameters which characterize an aftershock sequence and their interrelation, Journal of the Faculty of Science, Hokkaido University, Series VII, 2, 129-195.

Utsu T., (1971), Aftershocks and earthquake statistics (2): Further investigation of aftershocks and other earthquake sequences based on a new classification of earthquake sequences, Journal of the Faculty of Science, Hokkaido University, Series 7, Geophysics, 3(4), 197-266.

Utsu T., Ogata Y., Matsu'ura R.S., (1995), The centenary of the Omori formula for a decay law of aftershock activity, Journal of Physics of the Earth, 43(1), 1-33.

Wessel P., Smith W.H.F., (1998), New, improved version of the generic mapping tools released, EOS, Transactions of the American Geophysical Union, 79(47), 579-579.

Wiemer S., (2001), A software package to analyze seismicity: ZMAP, Seismological Research Letters, 72(3), 373-382.

Wiemer S, Mcnutt S., (1997), Variations in frequency-magnitude distribution with depth in two volcanic areas: Mount St. Helens, Washington, and Mt. Spurr, Alaska, Geophysical research letters, 24(2), 189-192.

Wiemer S., Wyss M., (2000), Minimum magnitude of completeness in earthquake catalogs: Examples from Alaska, the Western United States, and Japan, Bulletin of the Seismological Society of America, 90(4), 859-869.

Wiemer S., Wyss M., (2002), Mapping spatial variability of the frequency-magnitude distribution of earthquakes, Advances in Geophysics, 45, 1-40. 
Wiemer S., Katsumata K., (1999), Spatial variability of seismicity parameters in Aftershock Zones, Journal of Geophysical Research: Solid Earth, 104(B6), 13135-13151.

Wiemer S., Mcnutt S.R., Wyss M., (1998), Temporal and three-dimensional spatial analysis of the Frequency-Magnitude distribution near long Valley Caldera, California., Geophysical Journal International, 134(2), 409-421.

Wyss M., Shimazaki K., Wiemer S., (1997), Mapping active magma chambers by b value beneath Off-Izu Volcano, Japan, J. Geophys. Res., 102(20), 413-433.

Wyss M., Schorlemmer D., Wiemer S., (2000), Mapping asperities by minima of local recurrence time: San Jacinto-Elsinore fault zones, Journal of Geophysical Research: Solid Earth, 105(B4), 7829-7844.

Wyss M., (2001), Locked and creeping patches along the Hayward Fault, Geophysical Research Letters, 28(18), 3537-3540.

Zengin E., (2005), Adlyaman fay zonunun kuzeydoğu bölümünün sismotektonik özellikleri, Frrat Üniversitesi Fen Bilimleri Enstitüsü, Yüksek Lisans Tezi, Elazığ. 